\title{
PEDAGOGICAL PRINCIPLES, PROBLEMS AND POSSIBILITIES IN ONLINE GLOBAL CLASSROOMS
}

\author{
Malcolm Beazley \\ University of Canberra \\ Malcolm.Beazley@canberra.edu.au \\ GPO Locked Bag, ACT, 2601, AUSTRALIA \\ Tel: + 6126201 2473, Fax: + 61262015360 \\ Julie McLeod \\ University of North Texas \\ jkmcleod@unt.edu \\ Lin Lin \\ University of North Texas \\ Lin.Lin@unt.edu
}

\begin{abstract}
This chapter provides an overview of pedagogical issues, problems, and possibilities in global online classrooms, with a particular focus on the communication component. Discussions of pedagogical principles, problems, and possibilities are based on reflections of international collaborative projects conducted through a global educational network named "Computer Pals Across the World” (CPAW), and are situated in important educational issues including context, commitment, collaboration and curriculum integration. It is hoped that these discussions will serve as a catalyst for further innovation and research in effective use of technology in global online classrooms.
\end{abstract}

Keywords: pedagogical principles, collaboration, enrichment, curriculum integration, teleliteracy; Computer Mediated Communication, global classrooms, ICT (Information Communication Technology)

\section{Introduction}

Already in 1981 forms of data communication were evident in universities and defense sites via a system called BITNET. Financial institutions, the travel industry and telephone companies, all made use of "communication networks" with instant access to information from another location nationally and internationally. While this was happening in the world at large, various types of teleconferencing methods started to be used as a tool in the K-12 classroom and in the provisioning and delivery of education to remote locations. These included audio (where individuals could use a single handset, 
loudspeaker phones or conference terminals to communicate with their peers in a remote site), audiographic (where the telephone was used in combination with any form of graphics communication such as facsimile, digital scanner, telewriter, slow scan television, etc.) and video (involving video and audio transmission). Teleconferencing as a management and training tool has been around since the 1960's, with numerous examples dating back to 1935. The "School of the Air" in Australia has been a very powerful initiative in overcoming the "tyranny of distance" with the idea being conceived as early as 1945 to enhance correspondence lessons (Robson, Routcliffe \& Fitzgerald, 1991).

The development of computer technology and its use in schools and homes brought with it public data systems such as the Times Network System (TTNS) in the United Kingdom in 1980s, which could be accessed by those beyond commercial and government institutions. As these systems became more widely known, educators and school authorities began to explore their use for educational purposes. There were numerous early trials, mainly in the field of distance education. Schools were slow to dedicate a telephone connection as the modem was considered a luxury and the networks required a long distance dialup at an expensive cost just to establish a connection. With the support of local telecommunications carriers, a few schools began to use technology in creative ways to establish national and international projects in which students could work collaboratively.

Recent years have seen rapid development of computer communication technologies. Various social software and Web 2.0 technologies such as blogs, wikis, YouTube, Facebook, and MySpace have made online communication much easier, faster, and on a larger scale. Many issues that the pioneer educators were concerned with, issues such as scaling up and finding ways to provide support for the "hub" person in a more "automated" way, have been superseded by the emergence of Web 2.0 technologies while at the same time, new challenges and possibilities have emerged.

This chapter aims to discuss several important pedagogical principles, challenges and possibilities of communication technologies based on reflections from one of the pioneer global educational networks - "Computer Pals Across the World" (CPAW) (Beazley \& Horsley, 1993). CPAW (http://reach.ucf.edu/ cpaw/index.html) is a non-profit global educational electronic network, which was co-founded in 1983 by Malcolm Beazley, an Australian educator, and James Erwin, a computer consultant from the USA. CPAW provides opportunities for people in educational and community institutions to share their experiences, ideas and knowledge in a variety of collaborative learning environments to enhance global understanding. It is operated and managed in over twenty countries by dedicated educators and citizens who donate their voluntary services and expertise. Over the years, the network has grown with its successes and challenges. We hope that our reflections will provide a pragmatic basis for discussion and serve as a catalyst for further innovation and research into effective use of technology in global online learning environments.

\section{PEDOGOGICAL PRINCIPLES}


Rapid developments in communication technology, particularly computer-mediated communication technology, have changed pedagogical implications of technology applications in teaching and learning. They offer new possibilities as well as place new demands and challenges on the teacher and learner. It was slowly realized that distance teaching and learning involves operating in different environments, often including different values, cultural mores and text interpretations. In any successful application of technology to distance education, it is imperative to have a sound knowledge and understanding of what has been tried before and to build upon the best practices from those experiences. While there have been rapid advances in online technology over the last twenty years, there have not been equivalent advances reflected in educational applications of online technology in K-12 education. In this part, we will focus on four important aspects of pedagogical principles: context, commitment, collaboration, and curriculum integration. Attention to these aspects played key roles in the success of projects carried out in the CPAW global network.

\section{1. Context}

Cognitive scientists maintain that the context in which learning takes place is critical (Brown, Collins \& Duguid, 1989; Godden \& Baddeley, 1975). Lave and Wenger (1991) suggest that all learning is contextual and embedded in a social and physical environment, and thus is situated learning. In contrast to traditional classroom teaching, situated learning assumes that the ongoing processes in which one is involved, for instance, the surroundings and social network of others doing the same thing, change the capacity for learning.

Any project using online communication in the teaching-learning process must take place in an educational context with defined strategies and outcomes. Vygotsky (1962) pointed out that one of the difficulties that a learner has in writing is that he or she addresses "an absent or an imaginary person or no one in particular" and thus has no motivation or feels no need to write, whereas in oral conversation "every sentence is prompted by a motive" (p. 99) to communicate to a person or audience. However, writing can be different in an online learning environment, where writing is usually intended for a finite number of participants and with particular purposes; the writing becomes a tool for exchanging information, interacting with the others, and challenging opinions among a group of learners. In essence, writing has an authentic purpose immersed in context.

The motives and context were present with CPAW from the very beginning. The potential for improving students' writing was realized with the availability and excitement of a real audience and so CPAW was born, starting with the early online exchanges between the Australian students and the Native American students.

CPAW was initially entitled “The AustralAskan Writing Project”, wherein students in Alaska and Australia began by exchanging letters of introduction. The information in the letters provided a sub-context for a number of follow-up exercises to take place in the months ahead. First, there was report writing, wherein students could write in-depth on one or more of the topics mentioned in the initial letters of exchange. The topics included 
food, hobbies, sport, music, history and other areas of cultural interest. Second, there was poetry writing, wherein students could write for an audience while learning about different poetic forms. Traditionally, many students in high schools did not always find the reading of poetry exciting, but poems written by someone they "know", (their virtual peer) proved to be more interesting. The third activity was electronic journalism as students reported on items of interest found in their local newspapers and in their schools, for instance, book reviews, television programs, travel information and advertisements, and sent them online to their peers. These articles were collected by the respective students and the classes compiled their own monthly newspapers. The next activity involved students in written dialogue on social issues. The social issues were very different in the two cultures, but the sharing activities provided a chance to think about the pros and cons of the issues. The concept of family and related issues proved to be a popular topic for discussion as was the topic of whaling, particularly with Norwegian and Japanese students. Finally students were encouraged to write scripts based on native legends familiar to them and to share them from their own perspectives. This activity provided multiple perspectives and interpretations of local legends (Black \& McClintock, 1995)

The geographical context of an online activity would vary depending on the number of students involved in the collaboration. Students within regions, districts or localities could be networked for collaborative practice. This was seen in many examples throughout the world including rural networks in the United States of America, particularly those in remote places like Alaska, Iceland, and the tele-cottage networks in Hungary and the indigenous community networks in the USA, Canada, New Zealand and Australia. Each collaborative network had a distinct context and character which underpinned and influenced the educational activities.

While the Internet continues to evolve and a particular locus may not be as isolated as it once was, it is very apparent that one of the motivators for students continues to be the differences in context that students will discover, just by virtue of their social interactions.

\subsection{Commitment}

Paulo Freire (1971) posits that a democratic education cannot be conceived without a profound commitment to humanity and recognition of the dialectic relationship between cultural existence as individuals and political and economic existence as social beings. Freire writes about the level of commitment of both the teachers and the students in a literacy program that he co-created with the teachers and the students. It was obvious that the true commitment of the students in the program began when they realized the power that came with the new capability of being able to read (such as being able to vote and get involved in local politics and change the course of their own quality of life). The teachers also saw the positive impact that the learning could have on their students' lives. As a result, there was a commitment of the:

- students to the reading and writing materials

- teachers to the students' learning

- students to their own quality of life 


\section{Chapter 2: PEDAGOGICAL PRINCIPLES, PROBLEMS AND POSSIBILITIES}

- teachers to co-create the curriculum in a "live" fashion with the students

- teachers to bring in relevant subject matter that would reinforce the positive, changing state of the individuals

- participants to examine the contradictions in thinking processes

- program sponsor's (Freire's) commitment to understand and reinforce rather than avoid what he saw happening on a larger level

Commitment was critical in the successes of CPAW projects. The parties involved, whether they were students, teachers or researchers must agree on a set of conditions on which the project would be based. These could include:

- duration of project;

- regularity of the communication;

- determining who will initiate the communication;

- $\quad$ some knowledge on the cultural background of those involved;

- $\quad$ knowledge of the general literacy level of students;

- ages of those communicating.

Often times a simple contract was enough to clarify what the participants were committed to. In CPAW projects, classroom to classroom exchange seemed to work more reliably and was sustained longer than individual to individual connections. This was because there was someone (usually the teacher) responsible for the operation of the projects.

Commitment can be made easier by the advances in technology. For instance, userfriendly technologies require less time, increase the span of control on the part of the participants, and facilitate collaboration and engagement.

\section{3. Communication and Collaboration}

Collaboration is the key to successful online teaching and learning in the K-12 classroom and beyond. In the CPAW projects, it has been found that one reason for not sustaining the communication is the difference in language abilities. If there is not a comparable standard of the common language in which the parties are communicating, then one party feels inferior and does not continue to respond. Similarly, if one party is not confident in the use of the technology then there is a lack of self-esteem. This is particularly so in countries such as Japan, where there is a standard of perfectionism. Furthermore, Liao (1996) reports that "Chinese people in Taiwan prefer safe topics in talking to each other, especially in turning from unacquaintedness to acquaintedness. However, safe topics differ interculturally” (p.1). Even with a perfect understanding of a singular concept, different cultures can often translate the goodness or badness of the situation differently based on their own prioritization of underlying values (Lin, 2006). Further cultural differences are highlighted by Marinho (2004) in her work with students from Brazil and Belarus. The differences in culture, language, generation, and learning styles will continue to present themselves as opportunities as well as challenges in online communication and collaboration. 
Successful collaboration in global classrooms depends on the participants having a good understanding of the culture and diversity issues in communication. Communication using computers, generally known as Computer Mediated Communication (CMC), is a much more sensitive means of communicating than many realize. While a general knowledge of the cultural backgrounds of those communicating is important, the lingua franca can cause many problems. In 1990 during the United Nations' International Year of Literacy, much formal recognition was made of teleliteracy (Beazley, 1990). This refers to an understanding and appreciation of the idiom and nuances of the common language being used in the global classroom. Without this knowledge, communication can produce what has become known as "flaming”, when heated exchanges and arguments can occur through misunderstanding of words and expressions. Emoticons such as : - ) or : - ( can be used to soften the impact of a word or expression if one is unsure as to how it will be received. Capitalizing an entire word can infer that the writer is "shouting." This is seen in certain cultures as impolite. One needs to be aware at all times that those communicating online are often from vastly different cultures (Scott, 1988). Teleliteracy acknowledges the need to read and write effectively in a global environment, using the technologies that make it possible to communicate with distant audiences.

In reviewing the impact of computer technologies on human development, Anderson (1988) commented how these technologies can change the lives of people. "Our tools," he says, "shape and change the way we live, the way we look at the world, the language we use and the way we interact with others"(p.107). Similarly, the Canadian sociologist and media ecologist, Marshall McLuhan noted long before the widespread use of ICT that "The medium is the message" (1962). McLuhan further explained that "the personal and social consequences of any medium result from the new scale that is introduced into our affairs by each new extension of ourselves or the new technology"(1962, p.17). The electronic medium changes the nature of the writing. In fact, a new language has developed called "netspeak," which is prevalent in younger generations because of frequent use of instant messaging contractions. E-mail (electronic mail), msg (message), asap (as soon as possible), fyi (for your information), imho (in my humble opinion), btw (by the way), u (you), cya (see you later), are but a few. In addition, the form of the electronic communication tends to be different from the conventional written communication as can be shown in a comparison of a convention letter and an electronic letter. Both the speed of writing owing to time constraints and the cost of communication have been responsible for these changes.

While the text has been the main medium for distance education, sibling technologies such as the telephone and/or video-recording often complemented the text. In CPAW this realization came during the first e-mail exchanges with the Australian and Alaskan students. The Alaskan students at first did not believe that the messages were being sent by real people. In fact, they were suspicious. To reassure them, audio conferences were established to support the written text. While the facelessness of the CMC is a positive factor in online communication for some learners, it can present an obstacle for others 
due to their different learning styles (Lin, Cranton \& Bridglall, 2005). The need for accent and pronunciation of the language could be best addressed via the oral or visual mode. For this reason, audio links often supported the written communication in a number of the projects. This was particularly so in the projects between indigenous and non-indigenous students.

Further examples of the use of "sibling" technologies to support CMC were seen in the use of video exchanges. The video letter exchange project often ran parallel to the CMC communication; however the communication time frame was much longer than the CMC communication. In their earlier stages, when there was not sufficient bandwidth and the networks were not mature, a combination of technologies would be used in CPAW projects. For instance, video letters involving students speaking on a video recording were sent via conventional airmail. Video recordings were used as a tool in the classroom for the hearing impaired students to capture their joy when communicating across the globe. Before the advent of this technology, hearing impaired students had little opportunity to communicate as the telephone was the only distance education tool.

Web 2.0 technology and social software have dramatically changed and refined the way we communicate and collaborate in the global learning environment. However, as well stated by Ong, "new media do not cancel out the old. They build on them, reinforcing them... radically changing their mode of existence and operation” (Farrell \& Soukup, 2002, p. 84)

\subsection{Curriculum Integration}

Many teachers remain hesitant about online projects, as they see them as additional work in the teaching-learning process. It is imperative that any use of the technology in distance education be integrated into routine classroom activities.

Several projects in CPAW successfully integrated online projects in classroom activities. These projects tended to fall into a number of categories based on the forms of communication which took place. The most common form of exchange was letter writing. Some teachers saw letter writing as the main form of communication and as an end in itself. As a result, they were not able to help sustain the communication between the students. When letter writing was carried out as a means to an end in the classrooms, or as a precursor to other projects, the communication became alive and continued. Information exchange was another form of communication which usually took place after the initial contact made through letter writing. Typically, students would work collaboratively from two or more locations in the world, focus on a specific topic, and share their ideas, perceptions and research. These online activities were carried out in much the same way as they were in a normal classroom where group work was used as a strategy. The extended or global classroom provided an enriched environment for students as they had access to a wider range of ideas from different cultures. The third form of communication was the online survey. Collection of data from multiple sites provided rich information and knowledge. Students, using the online survey, would seek ideas for classroom debates on topics such as "Whaling is Not Necessary". Multiple 
views of students in different countries made the content of the debate more erudite and authentic. Students became aware of various stands on a topic. They could receive relevant information more up to date than if they had read from a textbook, which would result in a more informed argument in the debate. Their computer pals could even alert them to media articles on the topic, which would not be readily accessible and often unknown, if the students were to rely on resources in the traditional classroom.

Simulations provided another popular activity in the global classroom. Such activity allowed for students to create imaginary environments which included their computer pals in other countries. Apart from providing sound and creative experiences, the activity imposed a certain discipline on the students as they had to make decisions on who could communicate with whom and under what conditions. The world of science fiction and other literary genre could be illuminated by this activity. For example, students might impersonate historical or fictional characters and communicate with their peers who had chosen another persona from the same novel or poem. This became a catalyst for interesting dialogue between the students as they were provided with an opportunity to think more carefully about the time, place and characters of a story.

Furthermore, students engaged in conflict resolution scenarios based on issues in the real world. For many years the online technology made it possible for students to ask an expert. There were a variety of projects based on this category. Students engaged with an expert or mentor to seek advice, information and knowledge on topics. This category usually assumes an older/younger dynamic with an element of emotional support and understanding as well as guidance. In much the same way as parents and citizens have provided support in many traditional classrooms in literacy and numeracy, the extension of this to the online classroom allows for greater flexibility as students can use the computer to contact their mentor at any time. Homework Online has operated for many years. Many early trials of this activity were carried out in Washington State, USA. Teachers make an agreement with their students to contact them online, at a certain time in the evenings or during the weekend to seek help on a problem associated with their assigned homework. This does place extra demands on the teacher but many teachers are happy to offer this service.

The following shows a number of applications, which have been used successfully by students in a number of countries over the years as part of or in association with the CPAW network (http://reach.ucf.edu/ cpaw):

- Remembering - a joint venture between CPAW and Chatback (an electronic mail network for children with disabilities based in the UK), where students swap interviews with war veterans.

- Acid Rain - students in Norway and Australia used specially designed technology to measure Acid Rain levels in their respective countries.

- Children's Millennium Challenge - the story of children's encounter with environmental problems in the world becomes the starting point for a discussion and "Children's Petition" to world leaders to save our environment before it is too late. 

Chapter 2: PEDAGOGICAL PRINCIPLES, PROBLEMS AND POSSIBILITIES

- From Bordeaux to Outer Space - French students from South-West of France (near Bordeaux) prepare an exhibition about a trip into space and a miniature model of our solar system. Students throughout the world were asked to send photos and information about their towns, themselves and their way of life.

- Building Electronic Bridges Between Generations - an intergenerational project where students and older persons engage in both written and verbal dialogue using computer and telephone technologies to discuss life in earlier days.

- International Writers' Week - an annual event where professional writers work with student writers to improve the craft of writing and to broaden their knowledge of literature. In addition student writers share their writing with their peers in other countries and with the professional writers who participate.

- Environment Watch - a program which provided a context for students to isolate global and local environmental concerns, develop skills and mechanisms to investigate the issues, implement environmental action plans and participate in the political process to lend support to the environmental cause.

- Singapore International Friendship Day - to promote world peace and friendship.

- Medicinal Plants Project - a comparison of plant species that can cure diseases with computer pals from a number of countries including Germany and South America.

The effectiveness of the CPAW is best summarized by Price (1988) who concludes, “The cultural exchange through writing and a variety of language-based activities have helped students develop a greater awareness of cultural patterns which are similar to and different from their own. The finer details of what to say, what to ask, when to write, how to respond, how to rephrase sentences and the need to select words more carefully, are but a few of the challenges that have played a major role in developing a greater understanding by individuals in their quest for knowledge” (p. 35).

In addition to theses applications the network has grown to target different audiences, all aimed at unlocking the barriers of isolation and loneliness as people are connected with their peers, who share common interests and problems. These include:

- Children in Hospital - based on the "stranger syndrome" where people often share their worries and problems with people whom they meet casually and who may not know anyone in common. Likewise children in hospital can communicate with other children in hospital to share their illness, treatments, concerns and the like.

- Seniors - basically this involves a tripartite format, as senior citizens communicate with each other on a variety of topics of common interest, seek information from specialist sources and/or communicate with students who are involved in intergenerational projects. Often seniors act as a mentor to students as they seek knowledge and advice under the supervision of the classroom teacher.

- Gifted and Talented Students - this has been of great significance for isolated gifted and talented students who need enrichment and challenge.

- Universities - empowering both pre-service and practicing teachers to use the online technology effectively to gain the best results in the K-12 classroom 


\section{Chapter 2: PEDAGOGICAL PRINCIPLES, PROBLEMS AND POSSIBILITIES}

Experience in the CPAW project has revealed that the replication of certain projects is not always successful owing to the different variables in the participating partners. Each online environment is different in that it has individuals with different expectations, backgrounds, and demands. This does not mean that all categories of projects outlined above cannot be replicated year after year. Similarly, one audience may be a more successful match for a project than another audience.

\section{Problems}

Postman (1992) describes technology as a "Faustian bargain" in which we must be aware of not only where technology benefits, but also where it detracts. While the previous section listed many positive realities for technology based learning, this section will address some of the problems that arise when using distance technologies in the classroom. Interestingly, when viewing the technology related problems through the lens of history, it is apparent that some issues have changed while others remain steadfast. For example, in the CPAW project, problems were identified and became known as "dragons" akin to the dragons in the popular simulation "Dungeons and Dragons." While there are many dragons, the following sample includes problems that still exist today in classrooms:

- The I (inertia) dragon is one of the most frustrating of all the electronic dragons. The inertia prevents any real progress in communication. One sends an initial message seeking a cooperative partner for a project and there is a reasonably quick reply from the recipient to agree to online dialogue but then nothing ever eventuates.

- The V (verbose) dragon is one who is responsible for costing an online partner unnecessary time and cost, as he/she writes too much. To assist such dragons a "to the point" format is encouraged so that each main point in a message is numbered, $1,2,3$, etc. to enable the recipient to read and respond to the contents more quickly.

- The $\mathrm{N}$ (not sustaining the communication) dragon writes infrequently, without informing the other party as to why.

- The R (response) dragon lacks the ability to synthesise or condense a series of messages from the same person and to respond to the salient points in one reply. The "to the point format" which students in the CPAW network adopted, ensured that each point in a message or series of messages could be addressed in one reply. This is better practice than writing a number of different e-mails or replying to a number of e-mails separately.

- $\quad$ The P (procrastination) dragon is living in hope that something will happen. While the individual is keen and willing to establish sustained communication, nothing ever transpires. There are many variables which create this “dragon” such as the lack of cooperation from senior staff and/or colleagues, lack of funding, insufficient access to computers and lack of confidence in the use of the technology or in the common language.

One particular problem that existed during the CPAW project that has changed is isolation. In the CPAW project, isolation of the teacher was a significant factor in the 
failure of online projects. The CPAW network addressed this issue by having a number of local/regional volunteer support people (mainly teachers) who would provide help to those in need in their region or locality. This local/regional technical assistance was the forerunner of today's "help desk" which service providers and institutions make available. However, if equipment had to be serviced in remote areas, the time for repairs to be made could be lengthy which became a major impediment to a project. In any use of ICT in formal teaching - learning projects, a support structure was always necessary, particularly on the school campus, if possible. The more support a teacher could be given to prevent a feeling of isolation, the better.

With new media and technology, the isolation problem can be mitigated. Various new media and social software make it easier to provide a support structure for teachers. In addition, teachers can use new technologies to collaborate between themselves. Further, it is well documented that teachers who integrate and use technology tend to be more collaborative and less isolated or private than teachers who do not use technology (see Riel \& Becker, 2008).

While there are a number of tactical problems that arise when using distance learning in the K-12 classroom, this chapter will focus on three of the most significant problems that arise: Internet safety, technology access, and curriculum integration. These problems are closely aligned with the above discussed pedagogical principles -- context, commitment, collaboration, and curriculum integration.

\subsection{Internet safety}

First and foremost, the safety of the students who connect to the world via the Internet is of primary concern. Because distance learning necessarily requires students accessing and sending information over the Internet, educators must be diligent about their safety. As noted above, the context of the classroom has significantly broadened with distance learning. Much student work is completed outside the control of the teacher, which has many positive benefits but also potentially exposes students to inappropriate information. Further, the collaborative nature of Internet-based student work allows students to connect with others worldwide, but not all those who are on the other end of the cable have the students' best interests at heart. Finally, creative Internet-based projects, particularly those that include photographs or videos of the children, can clearly offer predators valuable information about the students. Overall, protecting students is an important feature of the distance learning classroom.

In early iterations of the K-12 distance learning classroom using email addresses, the CPAW project addressed Internet safety by using one email address for the whole classroom. The email address was controlled by a teacher because one central email address was seen as more reliable and secure than students having individual email addresses. To help reduce the teacher's load in managing the central email, some students were nominated to play the role of project assistants. These students were responsible for clearing the messages each day and then distributing them in hard copy to their peers in the classroom. This practice provided a safe environment in which students worked 
without being threatened by the potential dangers which are so much part of today's cyberworld.

Obviously, this method may not be efficient nowadays. Other technologies such as blogs, wikis and discussion forums may provide a more open, flexible, and safe learning environment where the students can communicate freely and openly while at the same time monitor and be monitored by their peers. In addition, compared to prohibiting students from taking advantage of new communication tools, it is more important to help students understand the importance of protecting themselves and learn ways to protect themselves in online communication environments.

Recently, the concerns for children on the Internet appear in two forms: 1) protecting children from accidentally viewing inappropriate content on the Internet, and 2) protecting children from connecting with people via the Internet who aim to do harm to the child.

In 2001, the United States government, in response to concerns about students' safety online, implemented the Children's Internet Protection Act (CIPA) as a means to address the first concern, protecting children from accidentally viewing inappropriate content. Essentially under this act, schools and libraries that receive federal funds through the ERate program must have an Internet safety policy in place and use Internet protection measures such as Internet filters (Federal Communications Commission, 2006). E-Rate is a widely used federal program offering technology funding to schools and libraries in the United States. The legislation has been controversial for a number of reasons. Most importantly for this context, while students' information is filtered at schools and libraries, most home computers do not contain Internet filters. Thus, students who have access to the Internet at home can view websites that are in fact appropriate but still blocked at schools and libraries whereas students without access to the Internet at home cannot. In essence, students' access to information can be based solely on economic status (Miltner, 2005). Further, while Internet filters may offer comfort to adults, the technology is not foolproof. Clearly, some appropriate and necessary content is ultimately blocked and some inappropriate content slips through the filter. Thus, the comfort adults feel may be misplaced and even detrimental if it is relied upon at the expense of a well-rounded educational effort to keep students safe (Miltner, 2005).

Further, in 2006 the United States government considered legislation entitled Deleting Online Predators Act (DOPA) that targeted the second concern noted above, protecting children from connecting with people via the Internet who aim to do harm to the child. The DOPA act again targets schools and libraries that receive E-Rate funding and aims to protect children by prohibiting those schools and libraries from allowing students access to social networking sites and chat rooms (Library of Congress, n.d.). Social networking sites such as MySpace and Facebook and chat rooms offer teens a space to connect with others and "try on" different identities (Donath \& Boyd, 2004). Tapscott and Williams (2006) in their research on the Net Generation noted that networking is this generations' "modus operandi" and that social networking sites, chat rooms, text messaging and more were clearly the means with which the generation accomplishes their goals. At 
publication, this legislation is still pending and thus has not been fully evaluated and studied. However, there are already signs that this legislation will be as controversial as CIPA. There are two main issues with the legislation. First, some argue whether this issue is as dire as proponents state. In fact, the mainstream media in the United States has capitalized on the fear of online predators with highly successful reality based television shows like To Catch a Predator in which predators are lured out of their chat rooms with the hopes of meeting a child and then publicly arrested for the camera. However, others have demonstrated that children are statistically much more likely to be abducted or molested by people they know rather than people they meet online (Boyd \& Jenkins, 2006). Additionally, Tapscott and Williams (2006) state that more articles have been written about online predators than actual reported incidents of those predators online. Further, the National School Boards Association (NSBA) (2007) recently released research regarding social networking finding through extensive surveys of students and parents that actual incidents of worrysome behavior is low and that half of the students noted they used the sites to talk about educational topics. The second point of contention is whether the Internet filter is the best choice of action. Clearly, a technological solution is less labor intensive, but Boyd and Jenkins (2006) note that the broad definitions of social networking sites used in the legislation not only will filter MySpace and Facebook, but also legitimate and educationally appropriate blog sites and more.

In short, there are no easy answers to protecting children online. In fact, Warlick (2004) contends that protecting children from inappropriate information on the Internet is a literacy issue rather than a technology issue (see discussion under Possibilities below). Clearly, it appears that a judicious use of technology solutions along with ample education and communication may provide the most effective means of protection.

\subsection{Technology access}

Access to technology continues to be an issue for schools. While some teachers are willing to commit the time and energy to a distance learning project, the lack of access to technology can stymie the best laid plans. Further, collaborative projects require disciplined access to technology that is not always possible. During the CPAW project, an online questionnaire was sent to a sample of one hundred and forty-five students with the majority of the issues identified pointing to access. Specifically, the following issues were identified from the survey: unreliable phone connections, particularly where there is no dedicated line for the computer; connections drop-out during sending and receiving of text; modem difficulties and equipment servicing particularly in remote areas; lack of computer expertise in a school as many of the school based online projects relied on a dedicated teacher and if that teacher moved to another location the school would not necessarily continue a project; and lack of technical assistance either in the school or the local community, which was a common difficulty in rural and remote areas where a small school might rely on one computer for access to a communication network. Further outcomes from the questionnaire included: changes in service provider costs and/or regulations; unexpected interruption to the normal school schedule; and family and personal illness, misfortune or tragedy. On one occasion the reason responses were not being received by a group of students was that the teacher coordinating the project at the 
other end of the communication had died suddenly. While the specific technologies have evolved past modems for many schools, an underlying issue appear to remain: access to fully functioning technology resources.

As with all pedagogy, distance technology's success in the classroom depends on appropriate levels of funding, this in turn depends on the political whim of the day. More specifically, it depends on the priorities of those in political control at the time. This has been very evident in the past few years in many countries. The erratic funding which has been available for projects and research into ICT in the classroom is reflected in numerous projects which have come and gone. For example, ACTEIN (The Australian Capital Territory Education Information Network), based in Canberra, Australia was one such project (Huston, 1994). It was a collaborative initiative of all the universities in Canberra to introduce the Internet to primary and secondary schools in the Australian Capital Territory. What was unique about this project was its strong emphasis on technical and training support to accompany low cost Internet access. With the exception of many private schools, there is still a concern about the lack of training and onsite support for teachers, which is addressed in the next section. Clearly, ACTEIN is the exception rather than the rule and schools worldwide continue to struggle to adequately fund technology.

\subsection{Curriculum integration}

Because distance learning projects tend to connect students with others around the world, the cultural sensitivity of the communication can create issues. Clearly, students must be sensitized to other cultures and cultural norms. Further, collaborative and creative work typically takes longer than traditional lecture and textbook work and thus room must be made in the rhythm of the school for these types of projects. Finally, typical teachers' manuals and lesson plans available to teachers do not tend to make use of distance learning technologies. Therefore, teachers face many issues when attempting to integrate distance learning.

There is no doubt that the increasing access to the Internet in schools, has given rise to a pedagogical revolution in the classroom but the emphasis continues to be on the information technology more than the communication technology. The CPAW project expanded well beyond the original genre-based writing program, as the potential was realized for it to be an important application to other lessons. The use of the Internet as a tool in the classroom has allowed for much more creative use of the technology and the development of critical literacy skills (see Mioduser, Nachmias \& Forkosh, 2008). This is seen in a number of ways, particularly in web design and showcasing of work by students. However, there is a lack of human interactive pedagogy as is evident in projects like CPAW, where the focus was on both the "I" and "C" in ICT. The major use of the Internet tends to be for information seeking and collecting, with the only interaction being that between the student and the computer. While many students have their own email addresses, the educational use of this facility needs much more attention and research. The novelty of the Internet has superseded the technology which was used in the K-12 classroom of earlier days. There is a greater need to encourage the use of 
multimedia in the classroom to reflect the days when CPAW made use of the "sibling" technologies of the day to supplement the computer technology. Similarly, there is still a need for ICT integration in teaching and learning in the classroom.

When technology is available, it is historically made to conform to existing pedagogical practices rather than allowing those practices to transform the teaching and learning process. Indeed, Cuban (1986) documented a long line of technology, from the radio through television and to the computer, that have held promise for education and yet fallen short. In fact, Cuban cites many of the same reasons noted here. Additionally, Cuban notes what might be called the rhythm of the classroom where teachers have found the most efficient uses of their time and resist efforts to change those practices. Further, Papert (1993) notes that schools tend to change technology by sequestering it into separate classrooms and creating a curriculum centered around technology use rather than allowing the power of the technology in the students' hands.

Finally, Fitzgerald (2005) sees that educators have still not met the challenges of ICT integration in the classroom. While accessibility to the technology is getting higher, the effective manipulation of it in the classroom is still a concern. The provision of appropriate and adequate training at both the pre-service and in-service periods of teacher education is imperative if technology based pedagogy is going to have an impact on the curriculum. These are the challenges for the future, as educators build on the best of the past, to accommodate to the changing technology and contexts of the future. Research has shown that teachers need more than in-service training to fully integrate technology. They also need personal encouragement and mentoring, instructional mentoring, routine technical support and administrative technical support (Gopalakrishnan, 2006). In other words, they need to feel fully supported in their efforts. This support is even more necessary with the wider use of the Internet in the K-12 learning environment. Often there is one teacher who has responsibility as system's administrator, in addition to a teaching schedule and related duties. As a result, the problems encountered in the early use of ICT in the K-12 classroom have multiplied in recent years. The CPAW had major corporate sponsorship, a fully staffed secretariat was established in Sydney, Australia to provide both telephone and online assistance to teachers in ensuring the appropriate class to class matches were made (including student's age, interests, ability level, etc).

\section{Possibilities}

Fitzgerald (2004) believes that ICT in the classroom offers opportunities for new types of learning and cognitive approaches (see also Dede, 2008). Clearly, using distance learning opens the many pedagogical possibilities listed previously in this chapter. However, it is only relatively recently that such research into ICT and education has been made possible through certain government funded organizations. One such organization in Australia is The Learning Federation (TLF). This organization is jointly funded, on a fifty-fifty basis, by the Federal and State governments. The technology is increasingly being applied across the curriculum to involve students of all ages. This is evident in a number of trial projects, which include: 
- Science, where students (Years 5-8), join a team of palaeontologists working on a megafauna dig site. In this project entitled “Colossal Fossil”, students excavate the sites and prepare fossils for removal, using suitable archaeological tools. By using appropriate dating techniques to ascertain the age of the fossils students can identify the find.

- Social Studies, where students (Years 3-4), explore the life stories of a number of fictional characters, who live in the same house in Port Adelaide, over different periods of time between the 1850's and 1950's.

- Business and Enterprise, where students (Years 9-10), students simulate the management and running of a muffin bakery over a period of five days. They are encouraged to explore factors which affect maximum profit.

- Art, Design and Technology, where students (Years 7-8) bring new and different meanings to objects found in different locations as they reposition them in a new context of understanding and interpretation.

These are just a few examples of how the application of the technology has expanded from the early CPAW model to many more areas of the curriculum. In fact, the possibilities for distance learning in the K-12 classroom are vast, particularly if the above noted problems are addressed. Three specific areas in which the possibilities are the greatest for distance learning in the classroom include engaging the new digital learners, developing new digital literacies, and using Web 2.0 to enhance socially mediated constructivist learning.

Nikolov and Nikolova (2008) in this Handbook specifically discuss the changes in learning that have stemmed from the information or knowledge society, specifically noting that technology use is "rewiring" our brains. Further, Prensky (2001a; 2001b) describes young learners who have grown up with technology as "digital natives." These learners have preferences and characteristics such as viewing graphics before text, multitasking and collaborative learning that maintains digital connections with others. The digital natives differ from "digital immigrants" who did not grow up with technology and even if adopted will always have the "accent" of an immigrant. Clearly, the pedagogical practices noted in this chapter will resonate strongly with the digital natives, perhaps sparking a lifelong interest in learning or in a particular subject matter.

Clyde (1999) noted one issue for technology use is the changing nature of information technology skills necessary to effectively function in society. These skills are not limited to psycho-motor skills or navigating an application. Instead, the skills necessary can be broadly conceived of as new digital literacies, however specific definitions of these new literacies differ (see Mioduser, Nachmias \& Forkosh, 2008). Reading online is significantly different than reading physical text, not only in the demands it places physically on our eyes, but also because of hyperlinking. In fact, reading physical text can be thought of as two dimensional reading (across and down) whereas online text can be thought of as three dimensional reading (across, down and deep through hyperlinks) (Warlick, 2004). Hyperlinking also changes the ways in which writing can be accomplished online. Richardson (2006) calls writing online "connected writing" because of the ability to hyperlink. 
Leu, Kinzer, Coiro and Cammack (2004) studied literacy for many years and then used their knowledge to examine the literacies necessary when using the Internet. Specifically, they define new literacies as the ability to "identify important questions, navigate complex information networks to locate appropriate information, critically evaluate that information, synthesize it to address those questions and then communicate the answers to others." Clearly, parts of this definition are important literacy skills whether one uses the Internet or not. However, locating information in complex information networks is a skill that has become heightened with the sheer volume of information available on the Internet. Nobel Laureate Herbert Simon (as cited in Bransford, Brown \& Cocking, 2000) perceived this change when he noted that the definition of "knowing" is shifting to the ability to find and understand information. Additionally, Leu et al.'s (2004) definition does not specifically identify the type of media used to communicate the answers to others, the options for which have certain broadened with technology. As noted previously in this chapter, there is significant need to also focus on the "C" in ICT. Warlick (2004) identifies six ways in which students in the twenty-first century must be able to communicate to be considered literate: text, images, animation, video production, web publishing and programming. These six means of communication can all be addressed using distance learning in a K-12 classroom with Web 2.0 tools.

Web 2.0 can be described as a fundamental shift in the Internet tools available and in the ways the tools are used (O'Reilly, 2005). Web 2.0 tools are more collaborative and have a shorter learning curve than original Internet tools, essentially lowering the threshold for participation. In fact, combining solid research based literacy approaches with Web 2.0 tools has been shown to create authentic and organic learning opportunities for students (Vasinda, McLeod \& Morrison, in review). The distance learning K-12 classroom could make use of many Web 2.0 tools such as blogs, wikis, podcasts and digital storytelling, all of which would increase literacy skills, both traditionally defined and new literacies. Thus, the authors deem Web 2.0 tools as a powerful addition to any distance learning classroom.

\section{Concluding Remarks}

Clearly, distance learning applications hold much potential for K-12 learning communities. In areas such as context, commitment, collaboration and curriculum integration, global classrooms can advance important pedagogical principles, which could ultimately lead to widespread educational reform. These online communities are not without problems, however. Maintaining the safety of students while online, regularly accessing technology and creating classroom learning environments in which technology is seamlessly integrated are all issues that must be addressed in order to realize the full potential. Indeed, the payoff for successful online global classrooms include honoring the young minds that learn and process information differently, developing new digital literacies while maintaining the old analog literacies and creating collaborative spaces for students to construct meaning themselves; all of which leads to engaged learning by the students and teachers! 
Section 7: IT and Distance Learning in K-12 Education Chapter 2: PEDAGOGICAL PRINCIPLES, PROBLEMS AND POSSIBILITIES

\section{References}

Anderson, J. (1988). Australian education and technology. In Proceedings of the Australia Bicentennial Education Conference. Sydney: Australian College of Education.

Beazley, M. (1990). Teleliteracy- the challenge of a new age. In H. Milner (Ed.), Making the Difference. Proceedings of the Third Computer Pals Across the World Conference, Cairns, Austrailia.

Beazley, M., \& Horsley, M. (1993). Empowering teachers to use computers in communication: A resource book. Sydney, Ausralia: Aloha Learning International.

Black, J., \& McClintock, R. (1995). An interpretation construction approach to constructivist design. In B. Wilson (Ed.), Constructivist learning environments. Englewood Cliffs, NJ: Educational Technology Publications.

Bransford, J., Brown, A., \& Cocking, R. (Eds.). (2000). How people learn: Brian, mind, experience and school. Washington, DC: National Academy Press.

Boyd, D., \& Jenkins, H. (2006, May 26). MySpace and Deleting Online Predators Act (DOPA). MIT Tech Talk. Retreived August 26, 2007, from http://www.danah.org/papers/MySpaceDOPA.html

Brown, J. S., Collins, A., \& Duguid, P. (1989). Situated cognition and the culture of learning. Educational Research, 18, 32-42.

Clyde, L.A. (1999). Managing information technology in school library media centres. Englewood, CO: Libraries Unlimited.

Cuban, L. (1986). Teachers and machines: The classroom use of technology since 1920. New York: Teachers College Press.

Dede (2008)

Donath, J., \& Boyd, D. (2004). Public displays of connection. BT Technology Journal 

22(4), 71-82.

Farrell, T., \& Soukup, P. (Eds.).,(2002). An Ong reader: Challenges for further inquiry. Cresskill, NJ: Hampton Press.

Federal Communications Commission. (2006). Children's Internet protection act. Retrieved August 24, 2007, from Federal Communications Commission Web site: http://www.fcc.gov/cgb/consumerfacts/cipa.html

Fitzgerald, R.N. (2004). ICT: Challenges for creative learning. New Horizons in Education, 50, 16-23.

Fitzgerald, R.N. (2005). Understanding informal learning with technology: Insights for ICT integration. In P. Kommers \& G. Richards (Eds.), Proceedings of World Conference on Educational Multimedia, Hypermedia and Telecommunications (pp.948-954). Chesapeake, VA: AACE.

Freire, P. (1970). Pedagogy of the oppressed. New York: Continuum.

Godden, D. R., \& Baddeley, A. D. (1975). Context-dependent memory in two natural environments: On land and underwater. British Journal of Psychology, 66(3), 325-331.

Gopalakrishnan, A. (2006). Supporting technology integration in adult education: Critical issues and models. Adult Basic Education, 16(1).

Huston, M. (1994). ACTIEN pilot program report. Canberra: The Australian Capital Territory Education Information Network.

Lave, J., \& Wenger E. (1991). Situated learning: Legitimate peripheral participation. Cambridge, MA: Cambridge University Press.

Leu, D., Kinzer, C., Coiro, J., \& Cammack, D. (2004). Toward a theory of new literacies emerging from the Internet and other information and communications technologies. In R. B. Ruddell \& N. Unrau (Eds.), Theoretical Models and Processes of Reading, Fifth Edition (pp. 1568-1611). Newark, DE: International 
Reading Association.

Liao, C. (1996, October). Safe topics for first encounters in the Taiwanese society. Paper presented at the $21^{\text {st }}$ ALAA Conference, Nepean, Australia.

Library of Congress. (n.d.). Deleting online predators act of 2006. Retrieved August 25, 2007, from Library of Congress Web site: http://thomas.loc.gov/cgi-bin/query/D?c109:1:./temp/ c109BqJa8j

Lin, L. (2006). Cultural dimensions of authenticity. In P. Cranton (Ed.), Authenticity in teaching in higher education: New directions for adult and continuing education (pp. 63-72). New York: Jossey-Bass.

Lin, L., Cranton, P., \& Bridglall, B. (2005). Psychological type and asynchronous written dialogue in adult learning. Teachers College Record, 107(8), 1788-1813.

Marinho, V. (2004, August). Cultural identities in Mondialogo. On the Spur of the Modem, 5(2). Retrieved September 5, 2007, from http://reach.ucf.edu/ cpaw/2004CPAW\%20newsletter

McLuhan, M. (1962). Understanding Media: The extensions of man. London: Sphere Books.

Miltner, K. (2005). Discriminatory filtering: CIPA's effect on our nation's youth and why the Supreme Court erred in upholding the constitutionality of The Children's Internet Protection Act. Federal Communications Law Journal, 57(3), 555-578.

Mioduser, Nachmias \& Forkosh, 2008

National School Board Association. (2007). Creating and connecting: Research and guidelines on online social - and educational - networking. Alexandria, VA: NSBA. Retrieved August 23, 2007, from http://www.nsba.org/site/docs/41400/41340.pdf

Nikolov and Nikolova (2008)

O'Reilly, T. (2005). What is Web 2.0?. Retrieved September 23, 2006, from O'Reilly 
Web site: http://www.oreillynet.com/pub/a/oreilly/tim/news/2005/09/30/what-is-web-20.html?page=1

Papert, S. (1993). The children's machine: Rethinking school in the age of the computer. New York: Basic Books.

Postman, N. (1992). Technolopoly: The Surrender of Culture to Technology. New York: Vintage Books.

Prensky, M. (2001a). Digital natives, digital immigrants. On the Horizon, 9(5).

Prensky, M. (2001b). Digital game-based learning. New York: McGraw-Hill.

Price, C. (1988). The World at our Fingertips. In R. Czerniejewski (Ed.), Sharing in a Global Classroom. Proceedings of the First Computer Pals Across the World Conference, Alice Springs Educational Computing Association.

Richardson, W. (2006). Blogs, wikis, podcasts and other powerful Web tools for the classroom. Thousand Oaks, CA: Corwin Press.

Riel \& Becker, (2008). This Handbook

Robson, J., Routcliffe, P., \& Fitzgerald, R. (1991). Remote schooling and information Technology. Canberra: Australian Catholic University Inc.

Scott, A.P. (1988). Computer mediated conversations in education: Ritual, pedagogy and value. In R. Czerniejewski (Ed.), Sharing in A Global Classroom. Proceedings of the First Computer Pals Across the World Conference, Alice Springs Educational Computing Association.

Tapscott, D., \& Williams, A. (2006). Wikinomics: How mass collaboration changes everything. New York: Penguin Group.

Vasinda, S., McLeod, J., \& Morrison, J. (in review). LEA meets Web 2.0: Updating the approach.

Vygotsky, L. S. (1962). Thought and language. Cambridge, MA: MIT Press. 
Section 7: IT and Distance Learning in K-12 Education Chapter 2: PEDAGOGICAL PRINCIPLES, PROBLEMS AND POSSIBILITIES

Warlick, D. (2004). Redefining literacy for the 21st century. Worthington, OH: Linworth. 